University of Nebraska - Lincoln

DigitalCommons@University of Nebraska - Lincoln

Summer 2010

\title{
THE DEBATE AUTHORS WORKING GROUP MODEL FOR COLLABORATIVE KNOWLEDGE PRODUCTION IN FORENSICS SCHOLARSHIP
}

\author{
Gordon R. Mitchell \\ University of Pittsburgh - Main Campus, gordonm@pitt.edu \\ Carly Woods \\ University of Nebraska-Lincoln, cwoods3@unl.edu \\ Matthew Brigham \\ University of Pittsburgh \\ Eric English \\ University of Pittsburgh \\ Catherine E. Morrison \\ University of Pittsburgh \\ See next page for additional authors
}

Follow this and additional works at: https://digitalcommons.unl.edu/commstudiespapers

Part of the Communication Commons

Mitchell, Gordon R.; Woods, Carly; Brigham, Matthew; English, Eric; Morrison, Catherine E.; and Rief, John, "THE DEBATE AUTHORS WORKING GROUP MODEL FOR COLLABORATIVE KNOWLEDGE PRODUCTION IN FORENSICS SCHOLARSHIP" (2010). Papers in Communication Studies. 34.

https://digitalcommons.unl.edu/commstudiespapers/34

This Article is brought to you for free and open access by the Communication Studies, Department of at DigitalCommons@University of Nebraska - Lincoln. It has been accepted for inclusion in Papers in Communication Studies by an authorized administrator of DigitalCommons@University of Nebraska - Lincoln. 


\section{Authors}

Gordon R. Mitchell, Carly Woods, Matthew Brigham, Eric English, Catherine E. Morrison, and John Rief 


\title{
ARGUMENTATION AND ADVOCACY
}

\section{THE DEBATE AUTHORS WORKING GROUP MODEL FOR COLLABORATIVE KNOWLEDGE PRODUCTION IN FORENSICS SCHOLARSHIP}

\author{
Gordon R. Mitchell, Carly S. Woods, Matthew Brigham, Eric English, \\ Catherine E. Morrison, and John Rief
}

The disconnect between modes of knowledge production in forensics (mostly collaborative) and academic study in the humanities (mostly solo work) is a chasm that can complicate the transition from tournament competitor to professional scholar. Might arrangements that promote joint authorship help harmonize the two modes of knowledge production and convert creative energy from the forensics setting to the academic publishing enterprise? This essay considers the possibility, reflecting on how efforts to coordinate collaborative knowledge production in debate authors working groups relate to professional development challenges isolated in the 7974 Sedalia Conference, the 1984 National Developmental Conference on Forensics, the 1993 Quail Roost Caucus, and the 2009 National Developmental Conference on Debate. The analysis sheds light on issues of perennial importance for the forensics community and also contributes understanding of how recent technological and sociological trends portend changes in the process of knowledge production for the academy writ large. Key Words: co-authorship, argumentation and debate, forensics, academic scholarship, professional development

\section{The Debate Authors Working Group Model for Collaborative Knowledge Production in Forensics Scholarshit}

National developmental conferences often mark inflection points along an academic field's evolutionary arc. For example, the Speech Communication Association's 1971 "Wingspread Conference" produced The Prospect of Rhetoric (Bitzer \& Black, 1971; see also Porrovecchio, 2010), a landmark report that shaped a generation of scholarship in the field of communication. Just as Wingspread enabled leading rhetoricians to reflect on the past and

Gordon R. Mitchell, Department of Communication, University of Pittsburgh; Carly S. Woods, Department of Communication Siudies, University of Nebraska-Lincoln; Matthew Brigham, School of Communication Studies, James Madison University; Eric English, Department of Communication, University of Pittsburgh; Catherine E. Morrison, Department of Communication Studies, University of Rhode Island; John Rief, Department of Communication and Institute for Clinical Research and Education, University of Pittsburgh. This essay grew out of collaborative research by the Schenley Park Debate Authors Working Group (DAWG), a consortium of public argument scholars at University of Pittsburgh striving to generate rigorous scholarship addressing the role of argumentation and debate in society. First author Gordon Mitchell led work on this DAWG essay, second author Carly Woods provided extensive editorial guidance, original research, and written revisions. All of the co-authors contributed substantially in areas of conceptual design, research, writing and revision. Special thanks go to the pair of moose who freed the lead author from temporary confinement in the Wasatch Mountains in time to deliver an early draft of this paper at the 15th NCA/AFA "Alta" Conference on Argumentation, in August 2007 (http://alturl.com/p7vy). Correspondence concerning this article should be addressed to Gordon R. Mitchell, Department of Communication, University of Pittsburgh, Pittsburgh, Pennsylvania, 15208. Email: gordonm@pitt.edu 
plan for the future, the 1974 "Sedalia Conference" afforded a venue for key figures in forensics to take stock of the big picture challenges and opportunities facing their community (McBath, 1975). ${ }^{1}$

A prominent topic of discussion at Sedalia concerned the institutional status of intercollegiate debate programs. ${ }^{2}$ College forensics is a fascinating hybrid activity, part scholarship and part sport. The highly structured nature of competitive debate tournaments invites comparisons to the world of NCAA athletics (CBS Sports, 2005). Yet at the same time, debate's intensity makes it one of higher education's most demanding intellectual pursuits, serving as "an excellent training ground" for students to "learn research, organizational, and language skills" (Panetta, 1990, para. 4). The Sedalia conferees felt strongly that the long-term interests of forensics would be served best by an approach that prioritizes the scholarly dimension of the enterprise, rather than playing up the "horse race" aspects of forensics competition. For example, in a Sedalia position paper on "Future Goals and Roles of Forensics," Malcolm Sillars and David Zarefsky (1975) advanced the thesis that "scholars and teachers in forensics should define their interests primarily [emphasis added] in terms of their substantive scholarly concerns, rather than their roles as administrators of activity programs" (p. 83; see also Rieke \& Brock, 1975, p. 129-136). The Sedalia Conference report envisioned members of the forensics community coalescing into a research community that would tackle research questions on topics such as political campaign debates, conflict resolution, public opinion formation, and processes of persuasion (McBath, 1975, p. 35-36). But as Lee Polk and Donn Parson pointed out in response to the clarion call for scholarly debate research, "there is little in the suggestion of method by which questions should be answered" (as cited in McBath, 1975, p. 138).

In short, the Sedalia conferees shared a vision, but they suffered from a blind spot. The conference proceedings elucidated clearly the goal of the forensics community growing into a hub for academic research, but the means to achieve that goal received scant treatment. This is no minor oversight, as the challenge of converting creative energy generated from competitive forensics into momentum for academic knowledge production is a tall order. Chief among the obstacles is time, with numerous duties associated with administration of intercollegiate tournament activity crowding the tight schedules of forensics specialists, leaving precious few hours for scholarly projects. Another barrier is sociological in nature. In academia, the received view regarding humanistic research tends to be that scholarly

\footnotetext{
'In the following discussion, we have elected to use both the inclusive term forensics and the more specific debate, depending on the context. Although the authors' conclusions are shaped by their experience as primarily (though not exclusively) National Debate Tournament (NDT) and Cross Examination Debate Association (CEDA) participants, our research includes perspectives and insight from educators engaged in many forms of competitive forensics. By proposing alternative approaches for scholarly research by forensics specialists, the authors endorse the "spirit of Sedalia," a "tolerance and mutual respect for diverse points of view" (Zarefsky and Sillars, 2000, p. 54). We use the term debate in a more situated and narrow sense, to indicate when supporting research is specific to the practice of competitive debate, or when referring to the authors' experiences and perspectives. We recognize, however, that Sedalia's emphasis upon argumentation has been targeted by some as a barrier to robust and diverse research trajectories, particularly in individual events (Aden, 1991, p. 101). As a corrective, we have sought in this paper to supplement our argumentation-centric research with contributions from alternative perspectives on communication and forensics whenever possible.

${ }^{2}$ Our use of the term debate in this essay reflects our backgrounds in NDT/CEDA policy debate, but is not meant to privilege this style of debate over other styles such as parliamentary and Lincoln-Douglas debate. Participants in other styles of debate may share many of the experiences we outline, particularly relating to the competing demands that tournament travel and intellectual production place upon their time. Additionally, all forms of competitive debate share at least one key component: training in argumentative practice. It is our hope that the model we propose for synergy between debate participation and academic scholarship serves as an invitation for future considerations on how such a model might be adapted for participants in other styles of debate. That our model is rooted in argumentation gives us confidence in the potential of such cross-pollination to bear nourishing fruit.
} 
manuscript preparation is done properly in isolation: "Success in the academy depends largely on having one's work recognized as an individual accomplishment" (Ede \& Lunsford, 2001, p. 357; see also Schantz, 2008). Unfortunately, this model of solitary knowledge production fails to align smoothly with modes of labor honed in competitive debate, where interactions mostly involve teamwork. Group brainstorming sessions, practice debates, argument construction, and contest rounds each involve significant elements of intellectual coordination, of both competitive and collaborative varieties. The result is something of a mismatch, as young forensics competitors taught to think in groups are asked to labor in isolation as they attempt to navigate the transition to professional scholarship.

Despite Sedalia's blind spot, and the significant obstacles complicating the competitor-toresearcher transition, forensics scholars have managed to produce an impressive body of scholarship, with key articles appearing in the pages of this journal. And the community has continued to ruminate on its role in the academy (Parson, 1984; Dauber et al., 1993), most recently at the Third National Developmental Conference on Debate (Louden, 2010). Yet an unmet need persists for new modes of knowledge production that heighten the relevance and authority of forensics research and help replenish the supply of leading communication scholars with forensics backgrounds, as well as support new initiatives in undergraduate research and translational scholarship. Fortunately, recent trends in higher education create conditions favorable for such innovation.

Once a solitary enterprise, academic research is becoming an activity where, increasingly multiple scholars produce knowledge by working together in pairs or groups. In part, this trend is a natural response to the growing complexity and interdisciplinary nature of research topics, whose multifaceted dimensions often overtax the expertise and capability of solo investigators. But changes in the academy's information infrastructure also play a part in facilitating collective scholarly work. Digital interconnectivity, circulation of sophisticated social networking software, and the advent of flexible communication tools all make collaborative knowledge production ever more feasible (Woods et al., 2006). Amid commentary calling for new modes of knowledge production in the academy (Jensen, 2007) and more teamwork in rhetorical scholarship (Aune, 2007), surveys document an uptick of multiple authored publications in the field of communication (Kramer, Hess, \& Reid, 2007). How do these developments implicate forensics scholarship? In the pages that follow, we take this question as a point of departure, exploring how the prospect of collaborative knowledge production in argumentation bears on issues of professional development, institutional support for debate, and the fate of voluminous research briefs compiled by teams in preparation for tournament action.

Our analysis is informed by experimentation with a model of academic knowledge production designed to mirror key sociological patterns in competitive forensics. This model involves groups of scholars pooling labor in working groups to generate academic research, drawing upon skills honed during years of participation in debate tournament contest rounds. To generate preliminary insight on the dynamics involved in this process, we piloted a Debate Authors Working Group (DAWG) in our home city of Pittsburgh, Pennsylvania, creating a research consortium dedicated to co-production of debate-relevant scholarship. To ensure that research projects retain ties with academic debate, but also speak to a wider readership beyond the forensics community, our working group developed a two-fold scope requirement. According to this requirement, DAWG work products must either 1) make academic debating a point of departure for analysis engaging issues of concern for those beyond the debate community, or alternately 2) deploy an "outside-in" approach that uses 
analysis of academic debate as a destination point for scholarship that begins with treatment of topics relevant to wider society.

In the several years since our initiative began, DAWG scholarship has been published in Argumentation (Mitchell, 2010a), Rhetoric E Public Affairs (Mitchell, 2010b), Communication and Critical/Cultural Studies (English et al., 2007), The Quarterly Journal of Speech (Mitchell, 2006), and Contemporary Argumentation and Debate (Woods et al., 2006), as well as selected for publication in conference proceedings of the International Society for the Study of Argumentation (Rief, 2007), the Third Tokyo Conference on Argumentation (Woods \& Konishi, 2008), and the Alta Argumentation Conference (Mitchell, Woods, Brigham, English, \& Rief, 2009). Using these projects as a testing ground, our working group has honed processes of collaborative knowledge production, and developed guidelines that stipulate qualifying criteria for co-authorship and determine the order in which authors are to be listed in collaborative articles. These guidelines were endorsed by conferees at the Third National Developmental Conference on Debate (NDCD) held in 2009 at Winston-Salem, North Carolina, and taken under consideration by the American Forensic Association (AFA) at the 2009 National Communication Association Convention in Chicago, Illinois. In a related convention action, the AFA moved to co-sponsor, with the University of Pittsburgh Library System and the University of Pittsburgh Press, Timely Interventions: A Translational Journal of Public Policy Debate. Impetus for AFA co-sponsorship of Timely Interventions arose from the confluence of recommendations made by the Scholarship and Research Committee and the Tenure and Promotion Committee at the Third NDCD, especially both committees' calls for the AFA to support efforts by forensics specialists to pursue academically rigorous, collaborative scholarship. Here, we discuss these activities within the wider context of professional development challenges isolated in the Sedalia Conference (McBath, 1975), the National Developmental Conference on Forensics (Parson, 1984), the 1993 Quail Roost Caucus (Dauber, et al., 1993), and the Third NDCD (Louden, 2010).

Regarding the challenge of crafting frameworks for collaborative scholarship, we are mindful that there is a lot of catching up to do, as social science research programs (including some in the field of communication) have followed a pattern of multi-authored research for some time. Yet by the same token, we are hopeful that work toward development of a model of collaborative knowledge production in forensics scholarship will not only help address Sedalia's blind spot, but also contribute insight relevant to wider ongoing discussions about the role of creative work in an academy in flux.

\section{Debate as a Scholarly Endeavor}

Following a customary principle of debating practice, participants attending the 1974 Sedalia Conference kicked off the meeting by defining key terms that would guide conference deliberations. Accordingly, the group defined forensics as "an educational activity primarily concerned with using an argumentative perspective in examining problems and communicating with people" (McBath, 1975, p. 11). The significance of this move is underscored by Edward Schiappa's (2003) insight that definitions "put into practice a special sort of social knowledge-a shared understanding among people about themselves, the objects of their world, and how they ought to use language" (p. 3). In reflecting a "shift in thinking from forensics as activities to forensics as perspective for scholarship," Sedalia's definition of forensics "profoundly influenced subsequent deliberations" (McBath, 1975, p. 12). With the deliberations inflected in this way, the Sedalia conferees focused attention on how 
academic scholarship might add to the long-term vitality of intercollegiate forensics, bolster the intellectual freedom of participants, and engender mutually informing conversations between forensics scholars and interlocutors beyond the competitive community (Goodnight \& Mitchell, 2008). As the Sedalia conferees concluded, "Programs without any academic affiliation decrease the likelihood that the forensics specialist will be perceived as a scholar whose work is vital to the educational process, and increase the likelihood that competitive activity programs will be regarded as ends in themselves" (McBath, 1975, p. 14).

It is noteworthy that a mere ten years after the forensics community's first national developmental conference, Sedalia's ringing call for scholarly research "virtually disappeared from the agenda" of the Second National Developmental Conference hosted by Northwestern University in 1984, with the Evanston conferees having "virtually nothing to say" on the topic (Zarefsky, 1984). Why the silence? Perhaps there was a sentiment among conference organizers that Sedalia's call for redoubled scholarly research relating to debate had already been answered, rendering further dwell-time on the issue superfluous. It is certainly the case that in the years between Sedalia and Evanston, debate related scholarship flourished in a number of outlets, including the NCA-AFA summer conferences on argumentation (Alta conferences) and the Journal of the American Forensic Association. But there is a second, more troubling explanation that may account for the Evanston conference's exclusion of scholarly research from its agenda. An intensifying tradeoff between time spent in pursuit of contest debating and time spent in pursuit of research agendas by debate academics may have forced a choice resulting in Evanston's narrower developmental focus. Whatever the explanation, "the lack of organized discussion of Research and Scholarship at the Evanston conference was unfortunate" (Zarefsky, 1984, p. 1).

The institutional tie between forensics programs and academic departments is an arrangement that has historically provided stable homes for forensics teams. Such arrangements have also enriched the academy, as forensics scholars have played prominent roles in steering the nascent field of speech communication. ${ }^{3}$ For example, Douglas Ehninger and Wayne Brockriede used analysis of forensics to connect particular practices in the debate community with more general treatments of debate as a mode of democratic decisionmaking, thereby highlighting the importance of argumentation theory in the broader study of communication (e.g., Brockriede, 1972; Brockriede \& Ehninger, 1960; Ehninger, 1970; Ehninger \& Brockriede, 1972). Brockriede's doctoral dissertation advisor, Marie Hochmuth Nichols, broke into the study of communication as president of the Women's Debating Association at the University of Pittsburgh in 1930, and then went on to publish landmark essays in rhetorical criticism and serve as president of the Speech Association of America (Patton, 2001, p. 123-141; Woods, 2009). Academic luminaries such as Thomas Hollihan, Allan Lichtman, and David Zarefsky all honed their scholarly research acumen during the so-called paradigm wars of the 1980s and 1990s, when the Journal of the American Forensic

\footnotetext{
${ }^{3}$ In terms of the relatively underdeveloped scholarly study of individual events and parliamentary debate, the impact of this research upon the field of speech communication is harder to assess. There have been repeated calls for increased research on individual events and parliamentary debate in the recent past (Croucher, 2006; Harris, Kropp and Rosenthal, 1986; Kerber \& Cronn-Mills, 2005; Logue \& Shea, 1990; Porter, 1990; Rutledge, 1999), but they seem to suffer from Sedalia's blind spot as well; there has been little discussion of how this increase in research can be achieved in the face of the unique temporal and material demands upon the forensics specialist. This perhaps only intensifies the need for a collaborative model of forensics knowledge production, as those working with parliamentary debate and individual events teams share the same struggle to balance scholarship and competitive participation.
} 
Association carried waves of scholarly articles on facets of debate contest round theory and practice.

This rich history is one reason why G. Thomas Goodnight (1981) called for rapprochement of argumentation scholarship and debate practice at the second "Alta" argumentation conference, sponsored jointly by the Speech Communication Association and American Forensics Association. While some have taken Goodnight's cue and written about the entwinement of argument theory and practice in contest rounds (e.g., Kauffman, 1991; Mitchell, 1998; Munksgaard \& Pfister, 2005; Panetta, 1990; Rowland \& Fritch, 1989), the frequency with which forensics specialists produce manuscripts in the communication field has lessened as the pursuit of competitive success has become ever more labor intensive and central to the livelihood of forensics programs. In recent years, the tradition of debate scholars actively producing scholarship has receded, with the energy of forensics specialists increasingly channeled toward the chase for tournament trophies. In short, heightened sportification of the debate activity, general decline of interest in scholarly knowledge production on the part of forensics specialists, and erosion of tenure-stream faculty lines for directors of debate are but a few symptoms of this nascent problem Sedalia diagnosed but did not treat (Goodnight \& Mitchell, 2008). ${ }^{4}$

\section{Debate Sportification}

Horse-race hysteria and the attendant "hothouse" debating strategies for winning tournament trophies at all costs (Ehninger \& Brockriede, 1972, p. 313) present many forensics specialists with a Hobson's choice-produce academic scholarship or coach a successful team, but try both at your own peril. Travel schedules, cyclically renewing research assignments, and three or four day tournaments combine to exercise a temporal tyranny over those forensics specialists who struggle to find time for academic pursuits beyond the competitive tournament grid. ${ }^{5}$ This is not entirely a new trend; even during the Sedalia era, forensics leaders were keenly aware of the acute professional tradeoffs forced by the intense labor commitment involved in fielding a competitive team on the debate tournament circuit. ${ }^{6}$ Yet marathon tournaments, lengthier seasons, a research assistant "arms race," and a permanent, 24-hour research cycle resulting from ubiquitous online connectivity have combined to sharpen the coach vs. scholar tradeoff facing forensics scholars who wish to carve out academic careers. Should one choose to pursue a research agenda and the attendant promises of professional advancement, the choice risks exile from the place one once called home-the tournament site. Thus, two realms of communication theory and competitive praxis, which once worked in tandem so productively, become estranged. One result is that some of the most talented scholars are cornered out of the competitive debate activity because it does not allow them the time or incentive to work on other interests such as

\footnotetext{
${ }^{4}$ For instance, the Wake Forest Shirley Classic tournament piloted for several years a tournament with six preliminary rounds, recently returning to eight. Experimentation with more humane scheduling to enhance the quality of tournament life continues, with such modifications holding potential to clear room for the scholarly endeavors we endorse throughout this essay.

${ }^{5}$ While the travel schedule is still grueling for most debate teams, innovations brought about under the leadership of the late Ross Smith are showing promise in creating a more humane tournament experience. For instance, the Wake Forest Shirley Classic tournament has reduced its preliminary rounds to a total of six (down from eight) cutting the length of the day, prompting other tournaments to follow suit. Such moves not only provide for a healthier tournament experience but might also create room for the scholarly endeavors we endorse throughout this essay.

${ }^{6}$ Noting that forensics directors shoulder "a combination of teaching, coaching, travel, and administrative duties that boggles the mind," Zarefsky (1980) warned against the tendency of these duties to crowd out scholarly endeavors (p. 21).
} 
publishing and teaching (Parson, 1990, p. 70). This development is marked by accompanying shifts in nomenclature, with the sport-oriented "coach" terminology largely replacing terms like "forensics specialist"-the Sedalia conferees' preferred label for describing debate professionals (e.g., Hagood, 1975, p. 101; Holm \& Miller, 2004; Keele \& Anderson, 1975; Kerber \& Cronn-Mills, 2005).

Such trends have led to a situation in which fewer forensics specialists are expected to sustain scholarly research programs, especially when they do not hold tenure stream appointments at major research institutions. Further, those forensics specialists who do shoulder research obligations may find their employers insisting upon sole-authored publications to satisfy research expectations. Although we see some cause for hope that collaborative research will soon become more widely recognized as an authoritative form of scholarship throughout academe, single-author scholarship has long been the standard in the humanities. $^{7}$

Reflecting this general pattern, humanistic branches of the field of communication have generated only a modest output of group-authored works, or, as is termed in the sciences and social sciences, instances of "multi-authorship" (Gelman \& Gibelman, 1999; Gorraiz \& Wieland, 2009). Consider that the pages of this journal have carried 150 articles, excluding book reviews, between 2000-2008 (Vol. 36, Issue 3; up through 2008, Vol. 44, Issue 4). Of these articles, $99(66 \%)$ were single-authored, 34 (22.67\%) were co-authored ( 2 authors), and $17(11.33 \%)$ were multi-authored ( 3 or more authors). As we shall see next, these statistics shed light on another key difficulty encountered by forensics specialists seeking to establish professional research niches in academia.

\section{Scholarly Invention as a Social Act}

While the sheer intensity of labor involved in contemporary intercollegiate debate accounts for some of the difficulties facing young participants seeking to launch academic research careers, there are also sociological factors complicating the debater-to-scholar metamorphosis. Intercollegiate debate is a social activity shaped by both competitive and collaborative forces. While competitive pressures provide motivation for debaters to do research in order to defeat opposing teams, ésprit de corps spurs team members to work harder with each other on common projects designed to leverage contest round success. ${ }^{8}$

Before a debater presents a new argument at a tournament, for example, the idea is likely to have been brainstormed collaboratively with partners, vetted by other team members, and refined following coach feedback during practice sessions. The tournament setting adds additional layers of feedback coming from debate opponents and judges. In short, debaters are acculturated to internalize what Karen Burke LeFevre (1986) calls "invention as a social act." ${ }^{\prime 9}$ These elements of the tournament setting roughly resemble collaborative experiences,

\footnotetext{
7 That said, many landmark publications in the field of communication have been produced by such writing partners including, for instance, Kathryn M. Olson and G. Thomas Goodnight, as well as Wayne Brockriede and Douglas Ehninger.

${ }^{8}$ While parliamentary debate limits use of evidence in contest rounds, successful debaters still conduct various forms of research in order to maintain critical knowledge of current events, to use as argumentative resources and to understand the specific topic at hand, with a goal of being "well read" (Epstein, 1996; Gnehm, 1999). As such, we believe that our experience as NDT/CEDA participants reflects those of parliamentary debate in kind, if not in degree.

This culture of collaboration is, of course, not limited to debate. Examining forensics from an organizational communication perspective, Carmack and Holm (2005) explore the role of the squadroom as a space in which individual events competitors build a team culture. They observe that part of this process is the acquisition of new skills through collaboration: "As students discuss performances they have seen by competitors from other schools and
} 
which scholars in the social and medical sciences routinely internalize during their professional training, are elusive yet in "Platonic views of invention" that stress "recovery and expression of an individual's inner (and perhaps latent) voice or innate cognitive structures" (LeFevre, 1986, p. 2).

Forensics competitors are socialized into a rapid-reward economy in which their work efforts receive frequent scrutiny from varied audiences. However, the motivational spur provided by this instant feedback culture can become a hindrance when scholars face the relatively isolated existence of a sole researcher in academia. Accustomed to receiving frequent and dense feedback to their intellectual work two or three weekends a month at tournaments, new debate scholars face notoriously long peer review timelines in academic publishing. For journal submissions, authors can often expect to wait many months (even years) between rounds of editorial feedback. Even more, when a response is provided, it often represents nothing more than the intermediary mark for the project, offering little beyond a terse monologue rather than genuine dialogue between participants. And most basically, in an academic world where assessment criteria are often vague or even nonexistent, scholars find few counterparts to the tournament trophies and speaker point awards that motivate forensics competitors.

The Sedalia Conference advanced a powerful vision for forensics educators. Noting a growing disconnect between academic departments and forensic programs, Sedalia laid out a series of goals designed to bridge this divide. Unfortunately, although Sedalia's resolutions were helpful in imagining a new future for forensics, they were less useful in marking precise routes charting courses to such imagined futures. The Quail Roost draft document (Dauber et al., 1993) as well as the Evanston conference (Parson, 1984) suffered from similar limitations. Quail Roost participants emphasized their view that directors of forensics should be judged comprehensively in tenure and promotion decisions, but they did not consider fully the professional ramifications of reframing forensics scholarship in collaborative terms. Further, Quail Roost theorized few innovations designed to stimulate scholarly knowledge production beyond the tournament grid, at most referencing the need for forensics directors to have research assistants to help them in their presumably solitary publication activities. Deliberations at the Second National Developmental Conference on Forensics (Parson, 1984) sidestepped the research issue entirely (Zarefsky, 1984).

The debate authors working group model strives to link analysis of the debate community to larger issues facing the academy and world, either by using some element of forensics practice as a launching pad for academic inquiry, or by testing some academic finding with reference to the laboratory of forensics practice. This approach has potential to save forensics specialists time by allowing them to write about issues in their area of expertise, while also generating insight worthy of respect by colleagues in and out of the forensics community. As Robert Rowland notes, "co-authorship is a valuable means of letting scholars with different experiences work jointly on a project. I think it is particularly valuable for scholars whose time is limited as is the case for debate coaches or those with administrative appointments" (personal communication, November 5, 2007). Fortunately, the winds of change in academia are blowing in a favorable direction that may open opportunities for more experimentation 
on this front. The next section explores how a softening of the sole-author norm in the academy creates opportunities for new forms of forensics scholarship to emerge.

\section{A Whole Greater than the Sum of Parts}

Although co-authorship is common practice within academic fields such as medicine, economics, the natural sciences, and even some branches of the social sciences (Aonuma, 2001 , p. 7), the tradition of collaborative research is less well established in the humanities. Even though collaboration in text production has been theorized in composition studies, literary studies, feminist studies, and in the workplace, Lindal Buchanan (2005) claims, "despite its prevalence, the discipline currently lacks a model of rhetorical collaboration that can fully account for its many forms and multiple functions" (p. 133). In response, she identifies "productive" and "supportive" collaboration models. Productive collaboration aims at achieving an end product, with contributors laboring together to produce research and writing. Supportive collaboration involves contributors who indirectly influence an end product by providing support and social accommodation (p. 135). Buchanan articulates this division in order to better understand the history of women's rhetorical activities, yet the terms also explicate the role of collaboration in smoothing a debater's pathway into academic scholarship.

Even though the goal of co- and group-authored work is primarily productive collaboration (i.e. a group brainstorms, and then divides up the tasks in pursuit of a publication), the style of cooperation addressed in this article also has elements of supportive collaboration that may serve a transitional role for undergraduate debaters and forensics specialists both in and outside the tenure stream. Our experience suggests that co- and group-authored research socializes and provides resources for collaboration, enabling forensics specialists to get a foothold in the world of academic writing. For undergraduate debaters turned graduate students, it provides a support network much like the teams that supported their competitive and intellectual development. This type of supportive collaboration may include discussion of academic norms, such as evidentiary standards for scholarly publications, peer review protocols, assessment metrics, and mechanisms for introducing undergraduate students to the scholarly research community, and as we will discuss soon, even establishment of new outlets for scholarly publication. ${ }^{10}$ For forensics specialists in non-tenure stream positions who wish to gain recognition in academic circles, collaborative research provides a bridge from a service role to a scholar role, consistent with the forensics specialist's historical role in shaping the field of communication.

Co-authorship may be particularly well suited for members of the debate community because it enacts a familiar process of internal deliberation and argumentation. Mirroring the creation and refinement of argument briefs for competitive debate, the collabo-

\footnotetext{
${ }^{10}$ This type of mentoring can be pivotal for helping current and former debaters grasp how norms of academic research relate to the research skill sets they honed in intercollegiate debate competition. For example, it is important for young researchers to understand that the block quote system for citing evidence in contest rounds is not well-suited for scholarly writing, where an author's own ideas often define a work's significance and originality. Further, socialization regarding evidentiary standards is essential to enable young debate scholars to understand that forms of proof that might pass muster in the controlled chaos of a high-speed contest round will not likely pass through the more stringent filters of academic peer review. In general, academic referees spend more time, and apply more rigorous evaluative standards, when assessing creative work than their debate judge counterparts. Certainly this genre of insight can be passed down from a single senior scholar to a novice academic, yet the many-to-many interaction in collaborative group work provides a much more effective medium for this type of mentorship.
} 
rative brainstorming, revision, and decision-making that goes into co-authored scholarship involves reworking arguments for eventual presentation to wider publics. Debate teams have honed both formal and informal procedures for coordinating intellectual work. These procedures, driven primarily by the pressures of tournament preparation, constitute a rich storehouse of tacit knowledge that has proven very useful in developing the debate authors working group model. Consider that the following modes of engagement in the debate authors working group approach each have distinct correlates in the competitive forensics setting.

- Research area brainstorming and agenda setting, including roundtable discussion to project the upcoming year's academic projects and set research priorities (correlates with debate team research assignment brainstorming).

- Manuscript workshopping, featuring constructive criticism of drafts-in-progress generated from multiple perspectives (correlates with small group research teams working on focused debate assignments).

- Revision strategy and execution, involving group conversation regarding how best to respond to "revise and resubmit" peer review (correlates with debate team strategy sessions focused on how to adapt argument strategies in light of judge feedback).

- Delivery practice, executed in practice sessions for oral presentation of research reports to professional audiences (correlates with debate team practice rounds).

Our preliminary experience suggests that the debate authors working group model enables scholars to pool labor in projects spanning the creative spectrum, ranging from expansion of one-page concept papers, to refinement of convention paper rough drafts, to retooling of full drafts of manuscripts revised in response to refereed feedback provided by journal editors and peer reviewers. This process works for solo, co- and group-authored projects encompassing Buchanan's spectrum of "productive" and "supportive" collaboration discussed previously.

Furthermore, the occasion to work together on scholarly projects affords forensics authors opportunities to identify and develop points of overlap between the competitive forensics skill set and the skill set utilized in the generation of publishable academic work. Again, key research skills mobilized in the debate authors working group model have correlates in competitive forensics.

- Multi-tiered latticework of documentation: Many scholarly publications require authors to undergird their claims with multiple layers of support in the form of footnotes and citations (correlates with conventions of debate brief writing, with "extension" briefs backing up "front line" arguments).

- Esprit de corps: Authors depend on stimuli from others to break out of creative ruts and maintain writing momentum (correlates with patterns of social support forged in competitive forensics work groups).

- Audience adaptation: Successful authors learn to reach multiple audiences by adapting prose accordingly (correlates with the debater's inclination to adapt arguments for a rotating array of diverse judges and opponents).

- Division of labor. Scholarly work groups differentiate tasks and parcel them out based on skill specialization (correlates with a debate team's segmentation of assignments to maximize work efficiency).

The preceding lists illustrate how the debate authors working group model supports scholarly knowledge production by mobilizing skills developed in competitive forensics. 
This overlapping skill set correlates with work flow patterns that enable collaborating forensics specialists to "double dip" research efforts, for example by workshopping scholarly manuscripts during long van rides to and from tournaments, developing academic research projects during periods of down-time at the tournament site, or even using the judge feedback portion of oral critiques to brainstorm new scholarly projects growing out of arguments raised during contest rounds. But the model also promotes intellectual flexibility by drawing from the naturally eclectic and interdisciplinary knowledge base found in the forensics community. From the start, intercollegiate debaters are forced to think outside of and beyond disciplinary boundaries. Though ostensibly conducting "policy analysis," any competitive debater needs to be well versed in philosophy, critical theory, international relations, literature, and performance studies to tackle the challenging array of issues implicated in debate resolutions such as:

- "RESOLVED: That the non-communist nations of the world should establish an economic community" (1962-1963).

- "RESOLVED: That the federal government should control the supply and utilization of energy in the United States" (1973-1974).

- "RESOLVED: That one or more presently existing restrictions on First Amendment freedoms of press and/or speech established in one or more federal court decisions should be curtailed or prohibited" (1986-1987).

- "RESOLVED: That the United States Federal Government should substantially reduce its agricultural support, at least eliminating nearly all of the domestic subsidies, for biofuels, Concentrated Animal Feeding Operations, corn, cotton, dairy, fisheries, rice, soybeans, sugar and/or wheat" (2008-2009).

By engaging such diverse topics, debaters necessarily hone modes of thought and research that are detailed yet holistic, sophisticated yet flexible. However, when they enter graduate school, former debaters often face pressure to immerse themselves in a narrow disciplinary matrix and dramatically winnow their research focus. Such pressure can further complicate the competitor-to-researcher transition.

The debate authors working group model counteracts this phenomenon, enabling debate scholars to network with current and former debate colleagues. ${ }^{11}$ So connected, debate authors share a common intellectual identity, by virtue of their debate experience, yet also express an impressive range of intellectual, professional and scholarly interests. By activating these networks of potential scholars, former debaters can engage in collaborative research and publication that transcends disciplinary boundaries. A key strength of these scholarly networks flows from the widespread sense of intellectual curiosity within the forensics community. As Cass Sunstein (2007) notes, any group that does not maintain an atmosphere welcoming of dissent is vulnerable to group polarization and groupthink. Thanks to the

${ }^{11}$ The promise of interdisciplinary collaboration highlights a particularly valuable contribution to be made by individual events and parliamentary debate scholars. Forensics specialists interested in the study of individual events have emphasized the need for greater disciplinary and methodological diversity in forensics research (Croucher, 2006; Kerber and Cronn-Mills, 2005; Porter, 1990). We believe our model can be strengthened both by the inclusion of diverse perspectives cultivated by debate and individual events and the utilization of "currently underrepresented communication disciplines in forensics/individual events studies: interpersonal communication, organizational communication, small group communication, health communication, inter-cultural/cross-cultural communication, conflict management and resolution, non-verbal communication, and language and social interaction" (Croucher, 2006, p. 6) as well as diverse methods, such as "in-depth interviews, focus groups, participant observation, ethnography, phenomenology, ethnomethodology, symbolic interactionism, chaos theory/nonlinear dynamics, hermeneutics, historical/critical, experimental, quasi-experimental, case studies, laboratory experiments, process studies, comparative analysis, implementation evaluation, and evaluability assessments" (Kerber \& Cronn-Mills, 2005, p. 79). 
interdisciplinary nature of forensics training, forensics specialists can transcend some of the "turf wars" that typically characterize each discipline's desire to "one up" all others by pointing to its unique and exclusive claim to knowledge.

\section{Pitfalls of Collaborative Knowledge Production}

In response to concerns regarding abuses such as authorship inflation and downplaying the contributions of junior scholars and graduate students, there have been considerable efforts to address co-authorship as part of ethical research conduct (Drenth, 1998; Kwok, 2005). Professional associations, institutions, and research journals have developed sophisticated guidelines and practices to determine issues such as who may qualify as a co-author, how co-authors should be listed in a given article, and what forms of academic recognition are due to each scholar participating in a collaborative project (e.g., American Psychological Association, 2001; Biagioli et al., 1999).

Inspired in part by these examples, but noting that there is little discussion of collaborative research protocol within the communication field in general and the intercollegiate debate community in particular, our debate authors working group formed a committee to craft its own co-authorship guidelines. These guidelines (see Appendix I) provide a framework for intellectual collaboration that enables satisfying and rewarding production of high-caliber academic work in both social scientific and humanistic registers. In particular, this model spells out the necessary elements of collaborative writing when the clear authorial delineations made in the social, natural, and medical sciences are not available. They lay out the stages of knowledge production for each project, calling for the substantial involvement of all contributing authors in the key creative dimensions of conceptual invention, research and writing/revising (Jones, 2000, p. 13; Flanagin, Fontanarosa, \& DeAngelis, 2002). We envision these guidelines as a starting point for future debate authors working groups that seek to make transparent collaborative research responsibilities and obligations. There are already well-established norms of co- or group authorship in the social sciences. Now argumentation scholars have a similar reference point following the Third NDCD's adoption of the DAWG guidelines for co-authorship in collaborative scholarship.

The guidelines attempt to preemptively address potential controversies regarding who qualifies as an author and the order in which they should be acknowledged in published material. This is an important objective, given research showing that disputes stemming from co-authorship arrangements can negatively affect research team morale (Wilcox, 1998). Wolseley (1980) defines a co-author as "the writer of approximately half a book's text, sharing equally on space, earnings, and expenses, and participating fully in decision-making" (p. 20). However, real-world collaboration cannot always be so clearly divided (Day \& Eodice, 2001, p. 137; Fox \& Faver, 1984). Guidelines should attend to this issue by clearly enumerating the responsibilities of the lead author, senior author, and other co-authors. Since a key challenge involves convincing institutional audiences of the value of collaborative work products, the guidelines are also accompanied by a worksheet (see Appendix II) designed to make clear each co-author's contributions to any given project. Such transparency has potential to reduce the phenomenon of "honorary authorship," or "ghostwriting," a problem in the medical field where authors whose published contributions do not meet authorship criteria can be significant (Bates, Anic, Marusic, \& Marusic, 2004, p. 87-88; Laine \& Mulrow, 2005). Information disclosed in a DAWG author worksheet can also serve as a valuable resource in administrative assessment settings. For example, the worksheet received 
a favorable hearing during the lead author's 2007 annual faculty review, where a co-authored DAWG article was evaluated by a department chair seeking to calibrate judgments regarding annual research output of a single faculty member. According to Rowland, "multiple authorship is so common that there is not much problem at [our school] in getting credit for it." But as he explains further, "at institutions that question the value of such essays, however, the worksheet might be helpful" (personal communication, November 5, 2007; see also Rowland et al., 2010).

Future efforts to make collaborative contributions more transparent might involve publication of detailed contributor lists, which already appear in some journals (Yank \& Rennie, 1999). As the concept of collaborative knowledge production evolves in the forensics setting, methods to incorporate and acknowledge practical contributions to the research effort could develop in tandem. For example, it is possible to imagine several arrangements enabling undergraduate debaters to satisfy co-authorship requirements by contributing contest round research to collaborative research projects. ${ }^{12}$ Such a trend would mirror developments in research fields where practical contributions (e.g., providing patients or research material, carrying out a pilot study, collecting the data) already figure significantly in co-authors' self-disclosure of contributions to articles (Hoen, Walvoort, \& Overbeke, 1998, p. 218; cf. Bates et al., 2004).

\section{Thinking Outside the Tournament Box}

Our efforts to refine the debate authors working group model have been bolstered by a number of fortuitous factors. A conversation-friendly venue (the Schenley Park Visitor's Center in Pittsburgh, Pennsylvania) has provided a hospitable and inviting meeting place for us to gather on many occasions since 2006. The nearly 20 current or former forensics participants who have gone through the University of Pittsburgh's graduate program in communication during that period have constituted a critical mass of scholars needed to spark the project. And a supportive university administration has ripened institutional conditions for development of the collaborative research model.

The degree to which similar models may flourish in other settings lacking the same trifecta of favorable factors remains to be seen, but the forensics tournament site itself deserves careful consideration as a possible venue for scholarly collaboration. One criticism of the tournament space is that while it offers excellent training in knowledge production, this training does not always translate into proximate, tangible gains beyond the competitive grid, especially for debaters and forensics specialists who are committed to becoming scholars. For this reason, transforming the tournament space so as to offer new opportunities for scholarly development might provide individuals invested in both their scholarship and debate training with the time and collaborative possibilities necessary for success. ${ }^{13}$ One

\footnotetext{
${ }^{12}$ Involving undergraduates in the research process may hold particular value for parliamentary debate, which has a larger population of institutionally vulnerable student-run programs. By building connections to established researchers, participants in student-run programs would both strengthen the team's ties to the university at large, and provide greater perspective on the connections between theory and practice (Fayne, 1992; Kuster, 2003; Rutledge, 1999; for more on forensics teams and their organizational dynamic within larger university systems, see Holm \& Miller, 2004).

${ }_{13}$ Multiple forensics specialists have emphasized the tournament site as a promising venue for research (see Croucher, 2006; Dickmeyer \& Boerboom, 1999; Harris et al., 1986; Porter, 1990). We are encouraged by these efforts, however, we would add that in addition to viewing the tournament site as a gathering of research subjects, forensics specialists should approach participants as potential research partners, for the practical and pedagogical reasons listed above. The novice "teach-in," now a perennial feature of the annual policy debate tournament hosted by the University of Richmond, and the special event "debate-in" at the 2001 Shirley Classic Debate Tournament
} 
approach might involve incorporation of conference-like symposia into the tournament structure. By offering forensics specialists (and potentially debaters) release time from contest round work to present their research to top scholarly minds and receive feedback, those scholars committed to debate could achieve multiple objectives by attending tournaments. While this approach would demand a great deal of coordination, grants, and the willing participation of major players in the field of communication as well as others, such events would offer debate scholars the opportunity to attend tournaments and build their curriculum vitae simultaneously. They could be facilitated by one group or organized ad hoc as individuals contribute ideas and develop resources for additional meetings. The work at these symposia might translate into deeper coordination and collaboration before conference submissions are due and could potentially help debate scholars otherwise overwhelmed by their academic and coaching obligations to team up and produce high quality co-authored publications. In addition to providing outlets for forensics specialists to contribute insight to wider society, such arrangements also have potential to attract young scholars to the research profession during pivotal moments when they are contemplating career options.

Several scholars have suggested convincingly that the tournament site is a rich laboratory for testing skills in argumentation and advocacy, orality and style, interpersonal and small group dynamics, and organizational structures (Bailey, 1992; Dickmeyer \& Boerboom, 1999; Goodnight, 1981; Hagood, 1975; Kauffman, 1991; Rutledge, 1999). This is definitely the case, but competitive forensics tournaments have even more potential, especially when considering the possibility of collaboration and the depth and breadth of research conducted every year on important political and social questions. Rather than seeing tournaments as spaces where students put existent knowledge to work, we can envision them as sites to link up scholars within the forensics community to those who are producing knowledge in the broader academic and political world. Some debaters end up moving on to policy think tanks and other professional positions which allow them to affect policy (Muir, 1993). While this connection is well-established by empirical data (Colbert \& Biggers, 1985) the notion that debaters are somehow training for future jobs and have nothing to offer real world policy-making groups and governments in the near-term is shortsighted (Mitchell, 1998). Beyond the potential to collaborate on scholarly work, the tournament space offers the additional potential to become a site for generating fresh insights on policy topics of great importance to the United States and the international community. In addition to the conference-like symposia mentioned above, tournaments could host public policy convocations involving major political figures and thinkers invested in the given topic. By inviting actual policy-makers into the tournament space to engage in public debates, discussions, and interviews with college debaters and forensics specialists, the tournament site could itself become a unique research generator. Insights developed during these communicative encounters might fuel innovation both within the debate community and forge connections with other academic scholars, journalists, policy-makers, and citizens interested in topics discussed under the rubric of that year's intercollegiate policy debate resolution.

Sometimes undergraduate students convert their debate research into term papers, and occasionally more advanced scholars develop dissertations or scholarly articles from topic area reading they pursued while coaching. Yet for the most part the voluminous work products flowing from policy debate competition never reach wider audiences beyond the

hosted by Wake Forest University offer promising exemplars of ways the tournament structure can be modified to integrate enriching opportunities beyond the competitive grid. 
forensics community, and sometimes are never even read in contest rounds. This mothball effect is a shame, not only because the rest of the world might benefit from debate-driven insight, but also because young debaters and coaches stand to bolster their scholarly credentials by converting the fruits of their research into peer-reviewed scholarly publications (Hahn \& Luechtefeld, 2009; Spring, 2009).

The debate tournament site's potential to work as a translational pipeline for scholarly research presents unique opportunities for colleges and universities seeking to bolster their institutional infrastructure for undergraduate research. Numerous studies document the efficacy of undergraduate research programs in increasing student levels of intellectual curiosity (Bauer \& Bennett, 2003), improving graduate school placement rates (Summers \& Hrabosky, 2006), reducing minority student attrition (Nagda, Gregerman, von Hippel, Jonides, \& Lerner, 1998), and enhancing the overall undergraduate student experience (Bauer \& Bennett, 2003; Crowe \& Brakke, 2008).

The DAWG model, by integrating undergraduate students into the collaborative research process, has potential to replicate these outcomes. Institutional support for debate programs that embrace collaborative scholarship as a key mission component provide compelling responses to the Boyer Commission's (1998) call for the academy to prioritize undergraduate research.

According to Dorothy Mitstifer (2002), executive director of the Kappa Omicron $\mathrm{Nu}$ Leadership Academy, one key to effective promotion of undergraduate research entails socialization of undergraduate students into "sticky communities" of collaborative researchers. Such communities, thanks to their group cohesion and members' frequent, sustained contact, are able to provide the type of extended and intensive mentoring necessary for novice researchers to learn the dynamics of scholarly publishing. The intercollegiate debate community's makeup as a quintessential "participatory culture" (Goodnight \& Mitchell, 2008 , p. 89) yields the "stickiness" Mitstifer says can be instrumental in enabling young students to thrive as scholars.

Furthermore, the presence of senior scholars in the debate community connects novice researchers with publishing contacts and provides mentorship enabling students to place their work products in scholarly outlets in a variety of academic fields, including political science, computer science, philosophy, international relations, public policy, and communication. For example, initiative taken by senior debate scholars at the Third NDCD created an impetus for establishment of a new online, peer-reviewed journal, Timely Interventions: $A$ Translational Journal of Public Policy Debate (at http://www.timelyinterventions.pitt.edu). That journal features a 27 -member, interdisciplinary editorial board and is supported jointly by the University of Pittsburgh Library System and the University of Pittsburgh Press, as well as co-sponsored by the AFA.

The aim of Timely Interventions is to showcase debate's collaborative research model by providing such opportunities for mixed groups of researchers (undergraduate students, graduate students, and faculty, even from different institutions) to translate the fruits of contest round research into medium-length manuscripts suitable for rapid uptake by wider public audiences interested in the public policy issues being researched under the rubric of that years' intercollegiate debate resolution.

As with scholarly, peer-reviewed publications, prospective authors are invited to submit manuscripts to an editor-in-chief, who then solicits peer review from members of the editorial board. Peer reviewers are asked to apply evaluative criteria associated with quality debate argument (e.g. claims stated clearly and convincingly, arguments backed up by 
support, evidence thoroughly cited), as well as criteria associated with the challenge of translating "debate speak" into accessible prose understandable for a general, educated readership. This latter set of criteria is especially important, given the aim of Timely Interventions to cultivate a wide readership amongst policy-makers, journalists, citizens, and others interested in learning about that year's given topic area through a debate prism. As an online publication, Timely Interventions is designed to publish individual manuscripts serially, upon successful completion of peer review and copyediting, creating a mechanism for "high-velocity" scholarship.

The recent surge of resources flowing to undergraduate research in American higher education creates openings for non-tenure stream forensics specialists to tap fresh funding streams for their debate programs. Such requests for supplementary funding can be tailored to underwrite efforts by program directors and students to co-author translational research converting their contest round work into manuscripts suitable for publication by Timely Interventions and other scholarly outlets. With tournament competition reinforcing academic scholarship, the resulting finished articles could serve as powerful exhibits testifying to the intellectual rigor, pedagogical value and policy relevance of the debate activity in subsequent budget requests.

\section{Conclusion}

This essay has explored a model of collaborative knowledge production designed to convert the creative energy of intercollegiate forensics into rigorous academic scholarship. During the past several years, the experience of piloting a debate authors working group at our home institution has enabled us to test this model in practice, as well as theorize refinements needed to adapt the model for wider applicability. In this recursive process, the DAWG model exhibits qualities that Pippa Norris (2000) ascribes to "virtuous circles." Norris's analysis of political communication in postindustrial societies shows how certain patterns of human interaction build on each other in iterative fashion, with effects that "gradually ripple out" (p. 319) to other populations in a "ratchet of reinforcement" (p. 18). Preliminary indications suggest that the DAWG model ratchets out to wider groups along three interlocking vectors.

First, as founding DAWG members finish graduate work at our home institution and take appointments elsewhere, we encounter new colleagues and students who are enthusiastic about the prospect of collaborative scholarship, and in some cases, establish new DAWGs. Further replication along this vector is possible as scholars committed to collaborative knowledge production move through academe and share the "spirit of Sedalia" (Zarefsky \& Sillars, 2000, p. 54).

A second replication pathway involves formation of topic-specific DAWGs convened on an ad hoc basis to link scholars from multiple institutions together for work on particular research projects. For example, two undergraduate debaters recently taught at a debate workshop dedicated to improving high school students' research and speaking skills. Part of the curriculum involved teachers working with students to contribute directly to the U.S. presidential debate process. Following the workshop, the two undergraduate students folded discussion of their teaching experiences into a larger DAWG research project. By contributing statistical analysis, background research, and commentary, they were able to join the project as co-authors of a full-length scholarly manuscript (Zompetti et al., 2009). This group-authored manuscript features ten co-authors from five different institutions, including 
undergraduate students, graduate students, directors of debate, and tenure stream professors. Different portions of the text were generated at the debate workshop, an argumentation conference, an undergraduate directed study project, and electronically via email. The collaborative process entailed in the co-production of this manuscript provides hopeful evidence that the debate authors working group model can take advantage of digital connectivity and enable geographically scattered scholars to form productive knowledge production networks (cf. Tapscott \& Williams, 2008).

Third, forensics leaders and university administrators have lent backing and material support for development and application of the DAWG model. Nearly 100 forensics specialists gathered in Winston-Salem, North Carolina, from June 5-7, 2009, for the Third NDCD, an event that followed in the wake of similar meetings held in Sedalia and Evanston. During the Winston-Salem NDCD's closing plenary session, conferees took several actions in support of DAWG-type forensics scholarship. A resolution calling for the adoption of co-authorship guidelines for collaborative scholarship, modeled on Appendix I of this article, was approved by the NDCD body (Mitchell et al., 2010). Further, a report from the NDCD's Tenure and Promotion Working Group recommended establishment of an online journal "in order to validate the creative research produced by the collaboration of directors/ coaches and debaters" (Rowland, et al., 2010).

Debate's digital turn leverages efforts on the part of forensics specialists and debaters to pursue this form of collaborative scholarship. Debate teams have begun digitally scanning evidence and transporting their files on laptop computers, which are now ubiquitous at tournaments. In-round note-taking has gone digital too, with many debaters and judges keeping a "flowsheet" of contest round arguments on laptop spreadsheets. Pencils are gone; pens are becoming rare. Perhaps most importantly, widespread wireless connectivity links debaters together in ways that facilitate evidence sharing, argument scouting, results reporting, and interactive commentary about argument trends and practices on Internet discussion boards.

This positions the debate community on the leading edge of potentially seismic shifts in academe described by Michael Jensen, director of Web communications for the National Academies. According to Jensen (2007), the next wave of ("3.0") digital communication technology portends upheaval for traditional modes of academic knowledge production and assessment. As applications such as Wikipedia, digg, and del.icio.us continue to evolve and proliferate, demand will grow for forms of scholarship well adapted to an internetworked environment. The forensics community, with its impressive track record of quickly absorbing new information technology, disseminating information through online networks, and crossing disciplinary boundaries in the process of knowledge production, is an ideal source for the type of work products likely to have added value in the coming world that Jensen describes.

More widespread collaborative knowledge production in the forensics community will not guarantee a positive future for a sportified activity currently in flux and increasingly under scrutiny. But the prospect of forensics competitors pooling their talent and energy to share the vital lessons of forensics with the wider world at least brings into focus a number of hopeful possibilities. Grant monies could be awarded competitively to young forensics scholars wishing to buy out portions of their judging commitments at intercollegiate debate tournaments, freeing the scholars to work collaboratively on publishing projects at the tournament site. Rigorous and theoretically grounded systems for academic knowledge co-production could enable current and former forensics specialists to increase scholarly 
productivity, thereby strengthening the pillars of institutional support that enable intercollegiate debate to thrive over the long-term (Holm \& Miller, 2004). Instantiating norms and habits of co-authorship may also make conditions more favorable for argumentation scholars to pursue the sort of interdisciplinary research that is common in fields such as medicine and public health, where collaborative knowledge production is acknowledged as an essential response to the challenge of analyzing multifaceted phenomena. While the DAWG model opens new avenues for scholarly collaboration across disciplines, the field of communication is especially well situated to host these efforts (cf. McCroskey, 1998). Communication's broad focus supports study of the widest varieties of human affairs (Bitzer \& Black, 1971; cf. Porrovecchio, 2010), yet this breadth is tempered by the field's traditional linkage to the public, or the political-understood in its broadest sense as our social nature, humanity's need to be together.

Concern has been expressed regarding the forensics community's perceived lack of inventional resources to reach wider publics (Bailey, 1992; Bartanen and Frank, 1999; Weiss, 1985). By renewing collaborative ties between forensics specialists and the scholarly community, it may be possible to reinvigorate forensics' sense of public responsibility, while also delivering on Sedalia's promise to give the scholarly community a dynamic realm of applied practice: a laboratory in the most robust sense of the word.

\section{REFERENCES}

Aden, R. C. (1991). Reconsidering the laboratory metaphor: Forensics as liberal art. National Forensic Journal, $9(2)$, 97-108.

American Psychological Association. (2001). Ethical standards for the reporting and publishing of scientific information. Publication manual of the American Psychological Association (5th ed.). Washington DC: American Psychological Association.

Aonuma, S. (2001). What is a coauthor?: Scholarly publishing and problems of collaborative research. Journal of Kanda University of International Studies, 13, 1-16.

Aune, J. (2007, February 7). Graduate education and the organization of 'research'. Blogora web post. Retrieved July 31,2007 , from http://rsa.cwrl.utexas.edu/?q=node/ 1368

Bailey, R. J. (1992). Adding communication to debate: A look at parliamentary debate as a compliment to cross-examination debate in intercollegiate competition. Journal of the National Parliamentary Debate Association, 1(1), 25-27.

Bartanen, M., \& Frank, D. (1999). Reclaiming a heritage: A proposal for rhetorically grounded academic debate. Journal of the National Parliamentary Debate Association, 6(1), 31-54.

Bates, T., Anic, A., Marusic, M., \& Marusic, A. (2004). Authorship criteria and disclosure of contributions: A comparison of 3 general medical journals with different author contribution forms. Journal of the American Medical Association, 292, 86-88.

Bauer, K.W., \& Bennett, J. S. (2003). Alumni perceptions used to assess undergraduate research experience. Journal of Higher Education, 74, 210-230.

Biagioli, M., Crane, J., Derish, P., Gruber, M., Rennie, D., \& Horton, R. (1999). Council of science editor's taskforce on authorship. Retrieved July 29, 2007, from http://www.councilscienceeditors.org/services/atf_whitepaper.cfm

Bitzer, L. F., \& Black, E. (1971). The prospect of rhetoric: Report of the national developmental project. Englewood Cliffs, NJ: Prentice Hall.

Boyer Commission on Educating Undergraduates in the Research University. (1998). Reinventing undergraduate education: A blueprint for America's research universities. Retrieved June 7, 2010, from http://notes.cc.sunysb. edu/Pres/boyer.nsf/webform/images/\$File/boyer.txt

Brockriede, W. (1972). Arguers as lovers. Philosophy and Rhetoric, 5, 1-11.

Brockriede, W., \& Ehninger, D. (1960). Toulmin on argument: An interpretation and application. Quarterly Journal of Speech, 46, 44-53.

Buchanan, L. (2005). Regendering delivery: The ffft canon and Antebellum women rhetors. Carbondale: Southern Illinois University Press.

Carmack, H. J., \& Holm, T. T. (2005). Home sweet home: The role of the forensics squadroom in team socialization and identification. National Forensic Journal, 23(2), 32-53.

Colbert, K., \& Biggers, T. (1985). Why should we support debate? Journal of the American Forensic Association, 21, 237-40.

Columbia Broadcasting System Sports. (2005). The national collegiate debate championship-2004-2005. College Sports Television DVD. New York: CBS Sports.

Croucher, S. M. (2006). Special issue editor's introduction: Communication theory and intercollegiate forensicsAddressing the research void within forensics. National Forensic Journal, 24(2), 1-6. 
Crowe, M. \& Brakke, D. (2008). Assessing the impact of undergraduate-research experiences on students: An overview of current literature. Council on Undergraduate Research Quarterly, 28, 43-50.

Dauber, C., Balthrop, B., Bjork, B., Daniel, B., Hynes, T., Louden, A., ... Ziegelmueller, G. (1993). Report of the working committee from the quail Quail roost Roost conference on assessment of professional activities of directors of debate (Draft document). Retrieved August 1, 2007, from www.americanforensics.org/ProfDev/quail_roost.pdf.

Day, K., \& Eodice, M. (2001). (First person) $)^{2}$ : A study of co-authoring in the academy. Logan, UT: Utah State University Press.

Dickmeyer, S. G., \& Boerboom, T. (1999). Diversity of academic areas of interest among forensics participants. Speaker and Gavel, 36, 19-29.

Drenth, J. P. H. (1998). Multiple authorship: The contribution of senior authors. Journal of the American Medical Association, 280,219-221.

Ede, L., \& Lunsford, A. A. (2001). Collaboration and concepts of authorship. PMLA, 116, 354-369.

Ehninger, D. (1970). Argument as method: Its nature, its limitations and its uses. Speech Monographs, 37, $101-110$.

Ehninger, D., \& Brockriede, W. (1972). Decision by debate. New York: Dodd, Mead \& Company.

English, E., Llano, S., Mitchell, G. R., Morrison, C. E., Rief, J., \& Woods, C. (2007). Debate as a weapon of mass destruction. Communication \& Critical/Cultural Studies, 4, 222-26.

Epstein, S. B. (1996). What about research? How to be "well read." Joumal of the National Parliamentary Debate Association, 6(1), 3-13.

Fayne, G. D. (1992). Parliamentary debate: A call for faculty involvement. Journal of the National Parliamentary Debate Association, 1(1), 38-50.

Flanagin, A., Fontanarosa, P. B., \& DeAngelis, C. D. (2002). Authorship for research groups. Journal of the American Medical Association, 288, 3166-68.

Fox, M. F., \& Faver, C. A. (1984). Independence and cooperation in research: The motivations and costs of collaboration. Journal of Higher Education, 55, 347-59.

Gelman, S. R., \& Gibelman, M. (1999). A quest for citations? An analysis of and commentary on the trend toward multiple authorship. Journal of Social Work Education, 35, 203-13.

Gnehm, J. (1999). Specialized information: Marginalization and detriment to public argument. Journal of the National Parliamentary Debate Association, 6(1), 1-9.

Goodnight, G. T. (1981). The re-union of argumentation and debate theory. In G. Ziegelmueller (Ed.), Dimensions of argument: Proceedings of the second summer conference on argumentation (pp. 415-432). Annandale: Speech Communication Association.

Goodnight, G. T., \& Mitchell, G. R. (2008). Forensics as scholarship: Testing Zarefsky's bold hypothesis in a digital age. Argumentation and Advocacy, 45, 80-97.

Gorraiz, J., \& Wieland, M. (2009). Multi-authored publications: Their influence in the distribution of the financing costs in world licenses. Research Evaluation, 18, 215-220.

Hagood, A. D. (1975). Theory and practice in forensics. In J. H. McBath (Ed.), Forensics as communication: The argumentative perspective (pp. 101-110). Skokie, IL: National Textbook Company.

Hahn, T., \& Luechtefeld, S. (2009). Leveling the playing field: Improving accessibility for 'small schools' through open source debate. Paper presented at the 95th National Communication Association Convention. Chicago, Illinois. Copy on file with the lead author.

Harris Jr., E. J., Kropp Jr., R. P., \& Rosenthal, R. E. (1986). The tournament as laboratory: Implications for forensic research. National Forensics Journal, 4(1-2), 13-22.

Hoen, W. P., Walvoort, H. C., \& Overbeke, J. P. M. (1998). What are the factors determining authorship and the order of authors' names? Journal of the American Medical Association, 280(3), 217-218.

Holm, T. T., \& Miller, J. L. (2004). Working within forensics systems. National Forensic Journal, 22(2), 23-37.

Jensen, M. (2007, June 15). The new metrics of scholarly authority. Chronicle of Higher Education. Retrieved July 31, 2007, from http://chronicle.com/weekly/v53/i41/41b00601.htm

Jones, A. H. (2000). Changing traditions of authorship. In A.H. Jones \& F. McLellan (Eds.), Ethical issues in biomedical publication (pp. 3-29). Baltimore, MD: Johns Hopkins University Press.

Kauffman, C. (1991). Controversy as contest. In D. W. Parson (Ed.), Argument in controversy (pp. 16-19). Annandale, VA: Speech Communication Association.

Keele, L. K., \& Andersen, K. E. (1975). Professional preparation, status, and rewards. In J. H. McBath (Ed.), Forensics as communication: The argumentative perspective (pp. 144-155). Skokie, IL: National Textbook Company.

Kerber, A. G., \& Cronn-Mills, D. (2005). The state of forensic scholarship: Analyzing individual events research in the National Forensic Journal from 1990-2003. National Forensic Journal, 23(2), 69-82.

Kramer, M. W., Hess, J. A., \& Reid, J. D. (2007). Trends in communication scholarship: An analysis of four representative NCA and ICA journals over the last 70 years. Review of Communication, 7(3), 229-240.

Kuster, T. A. (2003). Realizing the treasured values of NPDA parliamentary debate. Journal of the National Parliamentary Debate Association, 9(1), 55-66.

Kwok, L. S. (2005). The white bull effect: Abusive co-authorship and publication parasitism. Journal of Medical Ethics, $31(9), 554-556$.

Laine, C., \& Mulrow, C. D. (2005). Exorcising ghosts and unwelcome guests. Annals of Internal Medicine, 143, 611-12.

LeFevre, K. B. (1986). Invention as a social act. Carbondale: Southern Illinois University Press.

Logue, B. J., \& Shea, B. C. (1990). Individual events research: A review and criticism. National Forensic Journal, 8(1), $17-27$.

Louden, A. (Ed.). (2010). Navigating opportunity: Policy debate in the 21st century. New York: International Debate Education Association Press.

McBath, J., (Ed.). (1975). Forensics as communication: The argumentative perspective. Skokie, IL: National Textbook Company. 
McCroskey, J. C. (1998). The future of communication education: Communication as a content discipline. In J. S. Trent, (Ed.), Communication: Views from the helm for the 27st Century, (pp. 191-194). Needham Heights, MA: Allyn \& Bacon.

Mitstifer, D. I. (2002). Integration of research and undergraduate education. Undergraduate Research Newsletter of the $U R C$, 7. Retrieved June 7, 2010, from http://www.kon.org/urc/urn_1_1.html

Mitchell, G. R. (1998). Pedagogical possibilities for argumentative agency in academic debate. Argumentation and Advocacy, 35, 41-60.

Mitchell, G. R. (2006). Team b intelligence coups. Quarterly Journal of Speech, 92, 144-73.

Mitchell, G. R. (2010a). Higher-order strategic maneuvering in argumentation. Argumentation. 24, 319-335.

Mitchell, G. R. (2010b). Switch-side debating meets demand-driven rhetoric of science. Rhetoric \& Public Affairs, 73, 95-120.

Mitchell, G. R., Bsumek, P., Lundberg, C. O., Mangus, M., Voth, B. with Hobeika, O., \& Jensen, M. (2010). Pathways to innovation in debate scholarship. In A. Louden (Ed.), Navigating opportunity: Policy debate in the 21st century (pp. 103-135). New York: International Debate Education Association Press.

Mitchell, G. R., Woods, C., Brigham, M., English, E., \& Rief, J. (2009). DAWG power: The synergy of writing in packs. In S. Jacobs (Ed.), Concerning argument (pp. 558-571). Washington D.C.: National Communication Association.

Muir, S. A. (1993). A defense of the ethics of contemporary debate. Philosophy and Rhetoric, 26, 277-296.

Munksgaard, J., \& Pfister, D. (2005). The public debater's role in advancing deliberation: Towards switch-sides public debate. In C. Willard (Ed.), Critical problems in argumentation: Proceedings of the thirteenth NCA/AFA conference on argumentation (pp. 503-509). Washington, D.C.: National Communication Association.

Nagda, B., Gregerman, S., von Hippel W, Jonides, J., \& Lerner, J.S. (1998). Undergraduate student-faculty research partnerships affect student retention. Review of Higher Education, 22, 55-72.

Norris, P. (2000). A virtuous circle: Political communications in postindustrial societies. Cambridge: Cambridge University Press.

Panetta, E. M. (1990). A rationale for developing a nationally competitive National Debate Tournament oriented program. Argumentation and Advocacy, 27, 68-77.

Parson, D. W. (Ed.) (1984). American forensics in perspective. Annandale, VA: Speech Communication Association.

Parson, D. W. (1990). On publishing and perishing: Some approaches in forensic research. National Forensic Journal, $8,69-72$.

Patton, J. H. (2001). Marie Hochmuth Nichols: Voice of rationality in the humane tradition of rhetoric and criticism. In J. A. Kuypers \& A. King (Eds.), Twentieth-century roots of rhetorical studies (pp. 123-141). Westport, CT: Greenwood Press.

Porrovecchio, M.J. (Ed.) (2010). Reengaging the prospects of rhetoric: Current conversations and contemporary challenges. New York: Routledge.

Porter, S. (1990). Forensics research: A call to action. National Forensic Journal, 8(1), 95-103.

Rief, J. (2007). Talking at cross purposes: Violating higher-order conditions with oppositional arguments. In F. H. van Eemeren, J. A. Blair, C. A. Willard, and B. Garssen (Eds.) Proceedings of the Sixth Conference of the International Society for the Study of Argumentation (pp. 1147-1154). Amsterdam: Sic Sat/International Center for the Study of Argumentation.

Rieke, R., \& Brock, B. (1975). Research and scholarship in forensics. In J. H. McBath (Ed.), Forensics as communication: The argumentative perspective (pp. 129-141). Skokie, IL: National Textbook Company.

Rowland, R. C., Atchison, J., Gerber, M., Buescher, D., Hunt, S., Galloway, R., McDonald, K., Jarman, J., Young, K., Hollihan, T. (2010). Status of standards for tenure and promotion in debate. In A. Louden (Ed.), Navigating opportunity: Policy debate in the 27st century (pp. 77-102). New York: International Debate Education Association Press.

Rowland, R. C., \& Fritch, J. E. (1989). The relationship between debate and argumentation theory. In B. E. Gronbeck (Ed.), Spheres of argument: Proceedings of the sixth SCA/AFA conference on argumentation (pp. 457-463). Annandale, VA: SCA.

Rutledge, S. (1999). Parliamentary debate: Where are we heading? Journal of the National Parliamentary Debate Association, 6(1), 26-30.

Schantz, M. S. (2008). Undergraduate research in the humanities. Council on Undergraduate Research Quarterly, 29, 26-29.

Schiappa, E. (2003). Defining reality: Definitions and the politics of meaning. Albany, NY: SUNY Press.

Sillars, M. O., \& Zarefsky, D. (1975). Future goals and roles of forensics. In J. H. McBath (Ed.), Forensics as communication: The argumentative perspective (pp. 83-93). Skokie, IL: National Textbook Company.

Spring, S. (2009). Weighing the case for open source debate. Paper presented at the 95th National Communication Association Convention. Chicago, Illinois. Copy on file with the lead author.

Summers, M., \& Hrabosky, F. (2006). Preparing minority scientists and engineers. Science, 317(5769): 1870-1871.

Sunstein, C. (2007). Republic.com 2.0. Princeton: Princeton University Press.

Tapscott, D., \& Williams, A.D. (2008). Wikinomics: How mass collaboration changes everything. New York: Penguin Group.

Weiss, R. O. (1985). The public presence of forensics. Speaker and Gavel, 23(1), 23-28.

Wilcox, L. J. (1998). Authorship: The coin of the realm, the source of complaints. Journal of the American Medical Association, 280(3), 216-217.

Wolseley, R. E. (1980). Should I collaborate? Journalism Educator, 34(4), 19-56.

Woods, C., Brigham, M., Konishi, T., Heavner, B. Rief, J., Saindon, B., \& Mitchell, G. R. (2006). Deliberating debate's digital futures. Contemporary Argumentation and Debate, 27, 81-105. 
Woods, C., \& Konishi, T. (2008). What has been exchanged?: Towards a history of the Japan-US debate exchange tour. In T. Suzuki, Y. Yano \& T. Kato (Eds.), Proceedings of the third Tokyo conference on argumentation (pp. 312-318). Tokyo: Japan Debate Association.

Woods, C. (2009). Debater-scholar-mentor: Feminist historiography, argumentation, and the search for excellence in the intellectual travels of Marie Hochmuth Nichols. Paper presented at the 95th National Communication Association Convention. Chicago, Illinois. Copy on file with the lead author.

Yank, V., \& Rennie, D. (1999). Disclosure of researcher contributions: A study of original research articles in The Lancet. Annals of Internal Medicine, 130, 661-670.

Zarefsky, D. (1980). Argumentation and forensics. In J. Rhodes \& S. Newell (Eds.), Proceedings of the summer conference on argumentation (pp. 20-25). Annandale, Virginia: Speech Communication Association.

Zarefsky, D. (1984). From Sedalia to Evanston: Assessing the decade. Discussion paper presented at the Speech Communication Association Convention. Miami Beach, Florida. Copy on file with the lead author.

Zarefsky, D., \& Sillars, M. O. (2000). AFA support for research: Journals and conferences. Argumentation and Advocacy, $37,48-59$.

Zompetti, J. P., Lamballe, A., Louden, A., Packer, J., Pfister, D., Smith, R., Von Burg, R., Williams, D.C., Zemlicka, K. \& Mitchell, G. R. (2009). DebateWatch 2.0: Argumentative engagement in the CNN/YouTube debate format. Unpublished manuscript on file with the lead author.

\section{APPENDIX I \\ DEBATE AUTHORS WORKING GROUP GUIDELINES FOR CO-AUTHORSHIP OF WORK PRODUCTS}

Revised from a draft document generated by the DAWG co-authorship committee. Polished and approved by acclamation at the December 1, 2006, DAWG meeting. Revisions approved April 22, 2007 (e-mail ballot). Adopted by the Third National Developmental Conference on Debate (June 2009).

The Debate Authors Working Group (DAWG) sees authorship as a significant aspect of academic research, one that deserves careful and rigorous treatment, given its ethical and professional implications. We believe that it is important that participants in the DAWG have a clear, common understanding of the standards for authorship at the outset of each project.

Given the history of outstanding co-authorship throughout the field of rhetoric, argumentation theory, and debate scholarship, it is surprising that there is still a paucity of guidelines for conducting collaborative research in this area. As intellectual collaboration is the lifeblood of intercollegiate academic debate, it is appropriate that sound and workable guidelines be developed for translating collective intellectual labor into professional argumentation scholarship.

\section{Co-Authorship GutDelines FOR THE Debate Authors Working GrouP}

It is our belief that the practice of co-authorship should involve the substantial involvement of all contributing authors. Substantial involvement is defined by the following criteria, which must be met by each individual who will be listed as an author in the final work. Under each major heading, there are several modes of involvement that contributors may select.

\section{A. Inventional Process:}

We recognize the importance of the initial phase of creation that helps to set the stage for collaboration in the first place and the importance of linking up with individuals throughout the process of writing and research who can make additional substantial contributions critical 
to the project's completion. For this reason, we believe that co-authors should be involved in the initial conception of the project, mapping the goals and methods for completion of the project, or contributing substantial intellectual labor throughout evolution of the project as goals and the overall conception of the piece shift and change to meet new understandings and research findings.

\section{B. Writing and Revising:}

We also recognize the importance of substantial written contributions to the collaborative work effort as these justify the use of the term "author" in the first place; however, we believe that "authorship" can be understood in a broader sense to include both the initial contribution of substantial writing or the contribution of substantial written revisions later on in the process. Both of these activities imply a deep investment in the construction of the work at hand. For this reason, a co-author may be understood as an individual who drafts substantial original material or makes written contributions by proposing substantial revisions throughout the process.

\section{Research:}

Given the importance of research both in terms of the production of scholarly works and the development of arguments for the intercollegiate academic debate contest round, it is our belief that it should play an important role in the collaborative process of co-authorship. For this reason, substantial contributions in this area include setting the initial research agenda through a cooperative process of identifying where the working group should seek out relevant information and what kinds of information are most important to the completion of the project, working through primary and secondary source material in order to identify the most important elements to include in the final project, and finally synthesizing the research that has been completed so as to craft a final coherent product.

\section{Final Approval:}

As with any collaborative work effort, it is important that all individuals involved, should they wish to be identified as authors, give their consent to the final project. This avoids confusion, controversy, and de-legitimation of the work effort after it has gone on to the publishing phase.

\section{Order of Authors}

To ensure that all participants have a common understanding of research responsibilities, and to avoid confusion, we believe that it is important to establish the order of authors, including a lead author and a senior author (if appropriate).

A. The lead author (listed first) will be responsible for:

- Contributing key written material;

- Corresponding with journal editors and conveying necessary information to other DAWG members involved in the project;

- Synthesizing material contributed by co-authors, e.g. by knitting together sections, generating thesis statements and implications or conclusions; 
- Confirming that the content contributed to the project meets the ethical and quality standards of the group;

- Making final decisions about the order of authors and those included in the acknowledgments.

B. The senior author (listed last) will be responsible for:

- Mentoring the first author in the above tasks;

- Providing senior leadership and guidance to the entire group of co-authors throughout the process, from development of the concept to final submission of the manuscript.

C. We believe that those who have made significant contributions (as defined above) are entitled to be included as co-authors. Where there is a clear difference in the size of these contributions, this will be reflected in the order of these authors.

D. All others who fulfill the criteria for co-authorship with equal contributions will be included in alphabetical order of their last names.

E. If all authors feel that they have contributed equally, this can be indicated in a footnote or by directing readers to the DAWG Co-authorship Guidelines. 


\section{APPENDIX II \\ DEBATE AUTHORS WORKING GROUP \\ CO-AUTHORSHIP WORKSHEET}

This worksheet breaks down a single scholar's contributions to the collaborative work product listed below. Word template available for download at http://bit.ly/dawgsheet

Name of co-author:

Title of article:

To qualify as a co-author, scholars must demonstrate "substantial involvement" in each of the following areas listed below: invention; research; writing and revising.

\section{Invention}

Circle at least one item and provide qualitative description of contribution in this area

- Involvement in initial project conception

- Assistance in mapping goals and methods for project

- Intellectual contribution to drive project evolution

\section{Research}

Circle at least one item and provide qualitative description of contribution in this area

- Involvement in setting research agenda

- Retrieval of primary or secondary source material

- Synthesis of research for presentation in article

\section{Writing and Revising}

Circle at least one item and provide qualitative description of contribution in this area

- Contribution of substantial written text

- Contribution of suggested revisions

- Execution of substantial revisions 
Copyright of Argumentation \& Advocacy is the property of American Forensic Association and its content may not be copied or emailed to multiple sites or posted to a listserv without the copyright holder's express written permission. However, users may print, download, or email articles for individual use. 